\title{
Bulos y mitos de Internet en la cura de heridas: campo de actuación de las enfermeras
}

Vivimos en la sociedad de la información y los medios digitales son los predominantes. Actualmente la información fluye, los contenidos multimedia imperan y las redes sociales son los foros de discusión más habituales, así como una fuente de información frecuente entre sus usuarios. Este escenario ha dado lugar a que los bulos en salud se hayan viralizado más rápido que nunca y con gran impacto en las personas que los reciben. La desinformación pone a la población en situación de riesgo y las enfermeras podemos intervenir proporcionando datos contrastados, evidencias científicas e identificando aquellos bulos en salud que vayan apareciendo. Pero ¿por qué se difunden tan rápidamente los bulos en Internet? La respuesta es compleja pero hay factores determinantes como la facilidad para crear cuentas en redes sociales y las lagunas legislativas que propician este tipo de actuaciones. Quienes difunden bulos lo hacen porque creen que son ciertos y que pueden ayudar a todos sus contactos, pero los motivos de quienes los originan pueden no ser tan bienintencionados (1).

En 2014 se popularizó una noticia que decía que el hospital Johns Hopkins (una de las instituciones más reconocidas en el tratamiento del cáncer), había afirmado que la quimioterapia era una "gran equivocación médica". Al ser un tema muy controvertido se empezó a compartir masivamente por todas las redes sociales y la noticia llegó a tener miles de "Likes". Esto hizo que Facebook automáticamente identificara la noticia como un artículo relevante, y por tanto apareció en las noticias de los muros de muchos usuarios. El propio hospital Johns Hopkins tuvo que emitir una nota aclaratoria ante la cantidad de personas que creyeron el rumor y se planteaban abandonar sus tratamientos (2).

En el ámbito de las curas de heridas, hay diversos mitos o bulos que confunden a la población pero que gozan de gran popularidad: "el ajo es un potente curandero de heridas, llagas y raspones", "el sol hace que se curen antes la heridas", "lo mejor para curar es el agua oxigenada y el alcohol de toda la vida", "un chorrito de mercromina y dejar secar al aire", "si se hace costra es que está curando bien"... estas son algunas de las creencias que con más frecuencia podemos leer y escuchar y de esta manera circulan consejos sin ningún fundamento científico como "mezclar tres dientes de ajo en una taza de vino, procesar y dejar reposar dos horas y después aplicar sobre la herida limpia y seca, dos veces al día" o "beber a diario el zumo de dos kiwis pelados, media taza de yogur natural y dos cucharadas de miel para favorecer la cicatrización" (3).

Estos consejos basados en creencias populares pueden interferir negativamente en el tratamiento convencional de las heridas e incluso empeorar su evolución. Por eso es importante tener presentes los siguientes indicios de calidad a la hora de seleccionar información sobre salud en Internet (4):

1. Uso de lenguaje: la ciencia utiliza palabras precisas para describir datos y hechos objetivables. La pseudociencia se nutre de términos imprecisos e incluso carentes de sentido.

2. Ausencia de evidencia científica contrastable: desconfía de los textos en los que se habla de "un estudio llevado a cabo en Wisconsin" o "los científicos afirman que...". Las recomendaciones en salud deben ir acompañadas de referencias exactas o al menos fácilmente identificables para que los interesados puedan acceder a los estudios originales.

3. Los testimonios no tienen el mismo peso que los datos. Los bulos se alimentan de supuestos testimonios pero la ciencia lo hace de datos y estudios.

4. Desconfía de las técnicas milenarias o ancestrales, especialmente si se exponen como "milagrosas".

5. Es probable que los bulos se acompañen de logotipos institucionales para dar credibilidad a lo que exponen, aunque los usen de manera ilícita. También se pueden acompañar de frases como "la OMS dice...", "el Gobierno dice..." Es conveniente comprobar que la fuente es fiable y el mensaje correcto antes de divulgarlo.

6. Los bulos perduran meses o incluso años, así que también es necesario comprobar este aspecto porque una noticia originariamente válida puede convertirse en bulo al perder su validez o incluso deteriorarse su contenido (teléfono escacharrado).

La facilidad con la que se difunden mensajes a través de los móviles nos hace especialmente vulnerables a la desinformación, por eso es importante que las enfermeras nos posicionemos como fuentes de información fiable y accesible. Si no somos tan accesibles como los contenidos online, los pacientes preferirán consultar a la web que a los profesionales sanitaros y la información sin rigor científico ganara terreno. Por otro lado las enfermeras debemos desarrollar un sentido crítico exquisito que nos capacite para filtrar la información ayudando a los pacientes a seleccionar sus propias fuentes de información fiable, y por supuesto no difundiendo nosotras mismas bulos y pseudociencias.

Desde la iniciativa "Comparte con Cuidado" se lanzan estas cuatro premisas para ayudarnos a decidir cuándo compartir o no un contenido en Whatsapp o redes sociales (5): 
1. Critica. Si ves un artículo sobre la salud en internet o en alguna red social, léelo críticamente, cuidadosamente. No leas solo el título. Los títulos tienden a ser atractivos y no siempre captan la realidad. Ten en mente primero si crees a los autores o a la fuente, si lo que escriben vale la pena y si puede ser aplicable para tu entorno.

2. Comprueba. Sobre todo si es un tema de salud controvertido, trata de consultar la fuente original y/o de verificar la información en sitios de organismos nacionales o internacionales.

3. Concluye. Una vez que hayas leído, reflexiona. Saca tus conclusiones. Piensa si estás de acuerdo con lo que leíste o si te parece interesante y por qué.

4. Comparte. Si crees que vale la pena compartir, hazlo, agregando una frase con lo que reflexionaste en el paso tres. Esto expondrá tu punto de vista e invitará a tus amigos a comentar. Vale la pena compartir información confiable, y también compartir cuando descubres información falsa.

En conclusión, podemos afirmar que el rol de las enfermeras se extiende al ámbito de la salud digital y aquí tenemos un amplio campo de actuación detectando bulos perniciosos, denunciándolos y generando contenido digital basado en evidencias que ayude a los pacientes a tomar mejores decisiones en su autocuidado.

\section{REFERENCIAS}

1. Dunn HB; Allen CA. Rumors, urban legends and Internet hoaxes. Proceedings of the Annual Meeting of the Association of Collegiate Marketing Educators 2005. [cited 13 December 2018]. Available from: http://pascalfroissart.online.fr/3-cache/2005-dunn-allen.pdf

2. McMacken M. Cancer Update Email -- It's a Hoax! [Internet]. Hopkinsmedicine.org. 2014 [cited 13 December 2018]. Available from: https://www.hopkinsmedicine.org/kimmel_cancer_center/news_events/featured/ cancer_update_email_it_is_a_hoax.html

3. Papa Pintor Y. Los mejores remedios naturales para cicatrizar heridas - Mejor con Salud [Internet]. Mejor con Salud. 2014 [cited 13 December 2018]. Available from: https://mejorconsalud.com/los-mejores-remediosnaturales-para-cicatrizar-heridas/

4. Cinco claves para que no te cuelen pseudociencia en lugar de ciencia [Internet]. Maldita Ciencia. 2018 [cited 13 December 2018]. Available from: https://maldita.es/malditaciencia/5-claves-para-que-no-te-cuelenpseudociencia-en-lugar-de-ciencia/

5. Santillán-García A. Redes sociales basadas en evidencias \#comparteconcuidado [Internet]. Enfermeria Basada en la Evidencia (EBE). 2014 [cited 13 December 2018]. Available from: https://ebevidencia.com/archivos/2787

Azucena Santillán García

Hospital Universitario de Burgos. ebevidencia@gmail.com 